\title{
PENGARUH LINGKUNGAN KERJA NON FISIK TERHADAP MOTIVASI INTRINSIK DAN KEPUASAN KERJA DI DINAS PENDAPATAN DAERAH BADUNG
}

\author{
I Made Handy Sentosa ${ }^{1}$ \\ I Gede Riana ${ }^{2}$ \\ ${ }^{1,2}$ Fakultas Ekonomi dan Bisnis Universitas Udayana (Unud), Bali, Indonesia \\ e-mail: handysentosa1234@gmail.com
}

\begin{abstract}
ABSTRAK
Tujuan penelitian ini adalah untuk mengetahui pengaruh lingkungan kerja non fisik terhadap motivasi intrinsik dan kepuasan kerja karyawan, serta pengaruh pengaruh motivasi intrinsik terhadap kepuasan kerja karyawan di Dinas Pendapatan Daerah Badung. Sumber data yang digunakan dalam penelitian ini adalah data primer dan sekunder. Populasi yang akan digunakan pada penelitian ini adalah sebanyak 187 orang karyawan. Sampel pada penelitian adalah keseluruhan populasi sebagai sampelnya. Teknik pengumpulan data menggunakan kuisioner. Teknik analisis data menggunakan analisis jalur (path analysis). Hasil penelitian menunjukkan lingkungan kerja non fisik memiliki pengaruh positif dan signifikan terhadap kepuasan kerja pada pegawai di dinas pendapatan Daerah Badung Mangusada. Lingkungan kerja non fisik memiliki pengaruh positif dan signifikan terhadap motivasi intrinsik pada pegawai di dinas pendapatan Daerah Badung Mangusada. Motivasi intrinsik memiliki pengaruh positif dan signifikan terhadap kepuasan kerja pada pegawai di dinas pendapatan Daerah Badung Mangusada.
\end{abstract}

Kata kunci: lingkungan kerja non fisik, motivasi intrinsik, kepuasan kerja

\begin{abstract}
The purpose of this study is to determine the effect of non physical work environment on intrinsic motivation and employee job satisfaction, and influence the influence of intrinsic motivation on job satisfaction of employees at Badung Revenue Service Office. Sources of data used in this study are primary and secondary data. The population to be used in this study is as many as 187 employees. The sample in the study is the entire population as the sample. Data collection techniques using questionnaires. Technique of data analysis using path analysis (path analysis). The result of the research shows that the non-physical work environment has a positive and significant influence on job satisfaction on the employee in the Badung Mangusada regional income office. Non-physical work environment has a positive and significant influence on intrinsic motivation on employees in the Badung Mangusada Regional revenue service. Intrinsic motivation has a positive and significant influence on job satisfaction at employees in the Badung Mangusada Regional revenue service.

Keywords: non physical work environment, intrinsic motivation, job satisfaction
\end{abstract}


I Made Hady Sentosa, Pengaruh Lingkungan Kerja Non Fisik Terhadap...

\section{PENDAHULUAN}

Instansi yang berbentuk pemerintahan atau swasta pada era globalisasi saat ini tentunya memiliki tujuan yang hendak dicapai melalui aktivitas yang dilakukannya. Instansi-instansi tersebut hendaknya memerlukan perencanaan dan pengelolaan sumber daya manusia yang sebaik-baiknya agar dapat mencapai tujuan dalam organisasi. Sumber daya manusia merupakan hal terpenting yang dimiliki suatu organisasi, salah satu implikasinya adalah bahwa investasi terpenting yang dilakukan oleh suatu organisasi adalah di bidang sumber daya manusia (Handoko, 2001). Oleh karena itu, agar sebuah organisasi dapat mencapai kinerja yang maksimal diperlukan perlakuan yang adil dan memuaskan pada sumber daya manusia yang bekerja pada organisasi tersebut.

Kepuasan pegawai dalam bekerja merupakan faktor yang harus diperhatikan oleh organisasi, dimana perhatian tersebut seperti memberikan kesempatan untuk berkembang dan mengurangi tekanan dalam bekerja sehingga pegawai dapat merasa nyaman dalam bekerja dan dapat meningkatkan kinerja karyawan itu sendiri (Mahesa, 2010). Menurut Kabungaidze dan Nomakholwa (2013) dengan adanya pegawai memiliki kepuasan kerja yang tinggi maka pegawai akan setia terhadap profesi pekerjaan yang dilakukannya. Kepuasan kerja merupakan respons afektif atau emosional terhadap berbagai aspek pekerjaan seseorang, dimana seseorang dengan tingkat kepuasan kerja yang tinggi memegang sikap positif terhadap pekerjaannya, sementara seseorang yang tidak puas dengan pekerjaannya memiliki sikap negatif tentang pekerjaan tersebut (Pushpakumari, 2008). Kepuasan kerja merupakan faktor yang mendorong 
pegawai atau karyawan lebih giat bekerja dan sekaligus sebagai motivasi dalam bekerja (Suwardi dan Joko, 2011).

Kepuasan kerja mempunyai peran penting dalam rangka mendukung tercapainya kinerja yang baik sesuai dengan tujuan instansi terkait. Instansi yang sangat perlu memperhatikan kondisi kepuasan kerja pegawainya disini yaitu pada instansi milik pemerintahan, karena instansi-instansi ini yang menekankan pada pelayanan yang sepenuh hati kepada masyarakatnya. Pelayanan yang diberikan oleh jenis instansi ini pun harus mengikuti standar pelayanan minimum agar dapat memberikan pelayanan publik yang baik kepada masyarakat. Hal yang sebaliknya terjadi pada lokasi penelitian di Dinas Pendapatan Daerah Badung terlihat kepuasan kerja pegawai masih kurang yang mengganggu kinerja pelayanan pegawai. Rendahnya kepuasan kerja pegawai terlihat saat peneliti mengamati aktivitas pegawai di dinas, dimana dalam satu bidang salah satu pegawai dinas merasa kurang nyaman atas tindakan pegawai lain yang biasanya memberikan beban kerja yang lebih. Pemasalahan lainnya dari wewenang atasan yang juga berlebihan dalam pemberian beban kerja atau tugas kepada bawahan yang membuat pegawai merasa terbebani. Organisasi harus memperhatikan kondisi ini supaya kinerja yang diberikan pegawai kepada dinas tidak terganggu dan dapat berjalan dengan optimal.

Lingkungan kerja nonfisik yang merupakan bagian dari kondisi lingkungan kerja pegawai juga sangat mempunyai pengaruh terhadap kinerja yang dihasilkan oleh pegawai, jika karyawan tidak mampu menciptakan lingkungan kerja yang penuh maka suasana kekeluargaan dan komunikasi yang baik antar 
I Made Hady Sentosa, Pengaruh Lingkungan Kerja Non Fisik Terhadap...

karyawan dapat dipastikan kinerja akan terganggu (Sedarmayanti, 2009: 21). Demikian pula halnya dengan pengendalian diri, Kepuasan kerja merupakan evaluasi yang menggambarkan perasaan seseorang terhadap pekerjaannya, apakah senang atau tidak senang, puas atau tidak puas dalam bekerja (Sintha, 2013). Menurut (Shalley, 2000) bahwa setiap karyawan dapat menunjukan rasa kepuasan kerja yang lebih tinggi atau lebih rendah ketika lingkungan kerja masuk ke dalam kriteria yang disukai oleh karyawan dalam hal kondisi pekerjaan yang membuat karyawan merasa nyaman. Jadi, perlunya perhatian organisasi terhadap lingkungan kerja agar tercipta suasana kondusif dan nyaman sehingga dapat meningkatkan kepuasan kerja karyawan.

Lingkungan kerja juga merupakan faktor yang dapat memotivasi pegawai dalam bekerja. Menurut (Rivai, 2004: 456), terdapat beberapa aspek yang berpengaruh terhadap motivasi kerja karyawan, yakni rasa aman dalam bekerja, mendapat gaji yang adil dan kompetitif, lingkungan kerja yang menyenangkan, penghargaan atas prestasi kerja, dan perlakukan yang adil dari manajemen". Lingkungan kerja merupakan kondisi internal maupun eksternal yang dapat mempengaruhi semangat kerja sehingga pekerjaan dapat diharapkan selesai lebih cepat dan lebih baik (Nitisemito, 2000:159). Kenyamanan lingkungan kerja seperti adanya keharmonisan dalam bekerja dapat memicu motivasi kerja pegawai untuk bekerja lebih baik sehingga pekerjaan akan dicapai secara maksimal (Rezita, 2014).

Organisasi perlu melakukan upaya untuk memenuhi kepuasan kerja pegawai dimana salah satunya degan pemberian motivasi sesuai dengan pendapat 
Sulistiyani dan Rosidah Dhermawan dkk. (2012) menyatakan motivasi berpengaruh terhadap kepuasan kerja karyawan yang ditunjukkan dengan dukungan aktivitas yang mengarah pada tujuan. Ghulam dan Sajid (2012) dalam penelitiannya juga menjelaskan kurangnya motivasi dapat menyebabkan guru kurang berhasil dalam mengajar. Perhatian yang lebih besar harus diberikan pada peningkatan motivasi kerja ini karena motivasi kerja sangat penting sebagai upaya untuk memahami kondisi kerja karyawan atau bahkan meningkatkan efisiensi dan efektivitas organisasi publik (Rainey dan Steinbauer 1999). Menurut (Martoyo 2000: 165) motivasi adalah kondisi mental yang mendorong dilakukankanya suatu tindakan dan memberikan kekuatan yang mengarah kepada pencapaian kebutuhan, memberi kepuasan ataupun mengurangi ketidakseimbangan. Hasil penelitian Musriha (2011) menjelaskan motivasi kerja secara signifikan mempengaruhi kepuasan kerja, yang menunjukkan bahwa motivasi kerja tinggi mengarah pada kepuasan kerja meningkat. Motivasi kerja memang sangat diperlukan oleh seorang karyawan untuk dapat mencapai kepuasan kerja yang tinggi meskipun menurut sifatnya kepuasan kerja itu sendiri besarnya sangat relatif atau berbeda antara satu orang dengan orang lainnya.

Penelitian ini dilakukan dengan tujuan yaitu 1) untuk mengetahui pengaruh lingkungan kerja non fisik terhadap motivasi intrinsik karyawan di Dinas Pendapatan Daerah Badung, 2) untuk mengetahui pengaruh lingkungan kerja non fisik terhadap kepuasan kerja karyawan di Dinas Pendapatan Daerah Badung, 3) untuk mengetahui pengaruh motivasi intrinsik terhadap kepuasan kerja karyawan di Dinas Pendapatan Daerah Badung. 
I Made Hady Sentosa, Pengaruh Lingkungan Kerja Non Fisik Terhadap...

Penerapan lingkungan kerja non fisik seperti adanya pelayanan terhadap karyawan dari segi keselamatan dalam bekerja akan membuat karyawan merasa aman dan nyaman sehingga dapat memotivasi diri pegawai secara intrinsik untuk menyelesaikan pekerjaan (Brown dan Tobias, 2010). Wicaksono (2013) mengungkapkan sikap kepemimpinan dan hubungan kerja karyawan yang merupakan bagian dari lingkungan kerja non fisik karyawan dapat membentuk motivasi intrinsik yang ada dalam diri karyawan saat melaksanakan pekerjaannya. Rochani C.A (2008) menyatakan terdapat pengaruh positif dan signifikan lingkungan kerja non fisik terhadap motivasi intrinsik kerja karyawan perusahaan Album Sankyo. Sari (2012) menjelaskan terdapat pengaruh positif dan signifikan lingkungan kerja non fisik terhadap motivasi intrinsik karyawan CV Sedulir Palembang. Lingkungan kerja non fisik berpengaruh positif dan signifikan terhadap motivasi intrinsik kerja karyawan ditunjukkan juga dari hasil penelitian yang dilakukan oleh Anwar (2013).

$\mathrm{H}_{1}$ : Lingkungan kerja non fisik berpengaruh positif dan signifikan terhadap motivasi intrinsik karyawan.

Jain et al. (2014) dalam `penelitiannya menemukan bahwa beban kerja, setres, lembur, kelelahan, kebosanan adalah beberapa faktor untuk meningkatkan ketidak puasan kerja. Pada fasilitas kondisi kerja yang baik sisi lain, penyegaran dan fasilitas rekreasi, kesehatan dan keselamatan, menyenangkan di tempat kerja meningkatkan tingkat kepuasan kerja. Osibanjo et al. (2014) menemukan bahwa menyediakan lingkungan kerja yang kondusif, cukup terjamin dan memastikan menyeimbangkan pekerjaan dengan keluarga dan memastikan bahwa beban pekerjaan tidak melebihi batas. 
Indrawati (2012) menyatakan bahwa lingkungan kerja non fisik juga dikatakan sebagai salah satu faktor penentu kepuasan kerja dengan nilai loading factor sebesar 0,824. Dapat dikatakan bahwa terdapat hubungan yang sangat kuat antara lingkungan kerja fisik dengan kepuasan kerja. Rumada dan Utama (2013) mengungkapkan lingkungan kerja fisik berpengaruh positif dan signifikan terhadap kepuasan kerja karyawan pada Hotel Taman Harum Ubud. Handaru (2013) menerangkan lingkungan kerja memiliki pengaruh positif dan signifikan terhadap kepuasan kerja karyawan Rumah Sakit "X".

$\mathrm{H}_{2}$ : Lingkungan kerja non fisik berpengaruh positif dan signifikan terhadap kepuasan kerja karyawan.

Motivasi dalam cangkupannya secara intrinsik dan ekstrinsik merupakan faktor penting dalam menentukan kepuasan dan kinerja karyawan (Ibrahim dan Veronica, 2015). Menurut Ibrahim dan Veronica (2015) tentang motivasi, dimana motivasi ini bersifat individual karena kebutuhan individu berbeda-beda dan oleh karena itu harus ditargetkan pada kebutuhan individu dan kelompok secara intrinsik yang akan lebih memuaskan karyawan dalam bekerja. Menurut Guritno dan Heru (2016) dalam penelitiannya pada karyawan PT JHOS GF Semarang bahwa semakin tinggi motivasi instrinsik yang dimiliki karyawan makan akan meningkatkan kepuasan kerja karyawan terhadap pekerjaannya. Indrawati (2012) mengungkapkan faktor penentu kepuasan kerja pegawai Bappeda Tabanan adalah motivasi dengan nilai loading faktor sebesar 0,845. Ini menandakan bahwa memang terdapat hubungan yang sangat kuat antara motivasi yang kuat dan efektif baik dari dalam diri karyawan maupun organisasi/perusahaan terhadap kepuasan kerja karyawan. Penelitian Baard et al. (2004) menyimpulkan bahwa 
I Made Hady Sentosa, Pengaruh Lingkungan Kerja Non Fisik Terhadap...

adanya pemenuhan kebutuhan intrinsik dalam diri seseorang akan berdampak terhadap kepuasan kerja dan serta kinerja yang diberikan oleh seorang tersebut. Nalendra (2008) menjelaskan terdapat pengaruh positif dan signifikan motivasi terhadap kepuasan kerja karyawan.

$\mathrm{H}_{3}$ : Motivasi intrinsik berpengaruh positif dan signifikan terhadap kepuasan kerja karyawan.

\section{METODE PENELITIAN}

Pendekatan yang akan digunakan untuk meneliti sumber masalah pada penelitian ini adalah pendekatan kuantitatif yang berbentuk asosiatif karena penelitian ini bertujuan untuk mengetahui hubungan antara dua variabel atau lebih. Lokasi penelitian dilakukan di Dinas Pendapatan Daerah Badung. Lokasi ini dipilih karena ditemukan masalah masalah yang terkait dengan lingkungan kerja non fisik, motivasi intrnsik dan kepuasan kerja. Ruang lingkup dalam penelitian ini antara lain, lingkungan kerja non fisik, motivasi intrinsik dan kepuasan kerja karyawan. Penelitian ini dilakukan kepada seluruh karyawan yang ada di Dinas Pendapatan Daerah Badung, tetapi tidak termasuk pemimpin perusahaan.

Variabel penelitian terdiri atas variabel bebas yaitu lingkungan kerja non fisik (X), variabel terikat yaitu kepuasan kerja karyawan (Y2), dan motivasi intrinsik karyawan (Y1). Kepuasan kerja merupakan hal yang bersifat individu setiap individu memiliki tingkat kepuasan yang berbeda-beda sesuai dengan sistem nilai-nilai yang berlaku pada dirinya, ini disebabkan oleh adanya perbedaan pada dirinya dan masing-masing individu. Celluci dan De Vries (1978) dalam 
Retnaningsih (2007) merumuskan indikator-indikator kepuasan kerja dalam 5 indikator yaitu 1) kepuasan dengan situasi kerja, 2) kepuasan dengan promosi, 3) kepuasan dengan rekan kerja, 4) kepuasan dengan atasan, dan 5) kepuasan dengan pekerjaan itu sendiri.

Teori Herzberg (2008:178-181), faktor yang berperan sebagai motivator terhadap pegawai, yakni mampu memuaskan dan mendorong orang untuk bekerja baik yang terdiri dari 1) achievement (keberhasilan pelaksanaan), 2) recognition (pengakuan). Wing (2010) indikator motivasi intrinsik antara lain: pencapaian hasil tugas, kepuasan individu, keikutsertaan anggota pada setiap aktivitas perusahaan.

Yusa (2011) menyatakan indikator yang digunakan untuk mengukur lingkungan kerja non fisik adalah sebagai berikut 1) pengawasan di dalam perusahaan berjalan dengan kondusif, 2) suasana kerja yang di rasakan karyawan dalam bekerja dengan sesame karyawan merasa nyaman, 3) sistem pemberian imbalan sudah sesuai dengan tugas yang di berikan, 4) perlakuan pimpinan yang baik terhadap karyawan dengan tidak mempekerjakan karyawan melebihi kemampuan karyawan, 5) rasa aman dalam tempat bekerja dengan menyediakan CCTV dan satpam, 6) hubungan sosial yang berlangsung secara humoris dalam suasana kerja antara karyawan.

Sumber data yang digunakan dalam penelitian ini adalah sumber primer dan sekunder. Sumber data primer penelitian ini adalah data yang didapat dari observasi langsung dan kuesioner yang disebarkan. Data sekunder dalam 
I Made Hady Sentosa, Pengaruh Lingkungan Kerja Non Fisik Terhadap...

penelitian ini adalah jumlah karyawan, sejarah perusahaan, struktur organisasi, serta klasifikasi kinerja berdasarkan kualitas dan kuantitas.

Populasi yang akan digunakan pada penelitian ini adalah keseluruhan karyawan yang ada di perusahaan, tidak termasuk pemimpin/owner perusahaan, jadi keseluruhan populasi yang ada di perusahaan tersebut sebanyak 187 orang karyawan. Sampel merupakan bagian dari jumlah dan karakteristik yang dimiliki oleh populasi tersebut, dengan adanya populasi sebanyak 187 orang maka pada penelitian ini akan menggunakan keseluruhan populasi sebagai sampelnya, alasannya adalah syarat penelitian hipotesis jumlah sampel minimal 30 orang (Sugiyono, 2010: 116).

Metode pengumpulan data yang digunakan dalam penelitian ini dengan cara kuesioner (angket), Merupakan teknik utama pengumpulan data dalam penelitian ini yang dilakukan dengan cara memberi seperangkat pertanyaan tertulis kepada responden untuk dijawab oleh responden yang sesuai dengan objek penelitian.

Penelitian ini menggunakan teknik analisis data yaitu analisis jalur (path analysis). Utama (2009: 135), Menyatakan analisis jalur merupakan perluasan dari analisis regresi linier berganda, untuk menaksir hubungan kausalitas antar variabel yang berjenjang berdasarkan teori. Penelitian ini untuk mengetahui pengaruh langsung dan tidak langsung. Pengaruh langsung dan lingkungan kerja non fisik (X) terhadap kepuasan kerja karyawan (Y2) ditunjukkan oleh koefisien jalur c dan d, pengaruh langsung lingkungan kerja non fisik (X) terhadap motivasi intrinsik 
(Y1) ditunjukkan oleh koefisien jalur a dan b, dan pengaruh motivasi intrinsik (Y1) terhadap kepuasan kerja karyawan (Y2) ditunjukkan oleh koefisien jalur e.

Pengaruh tidak langsung lingkungan kerja non fisik (X) terhadap kepuasan kerja karyawan (Y2) diperoleh dengan mengalikan a dengan e dan b dengan e.

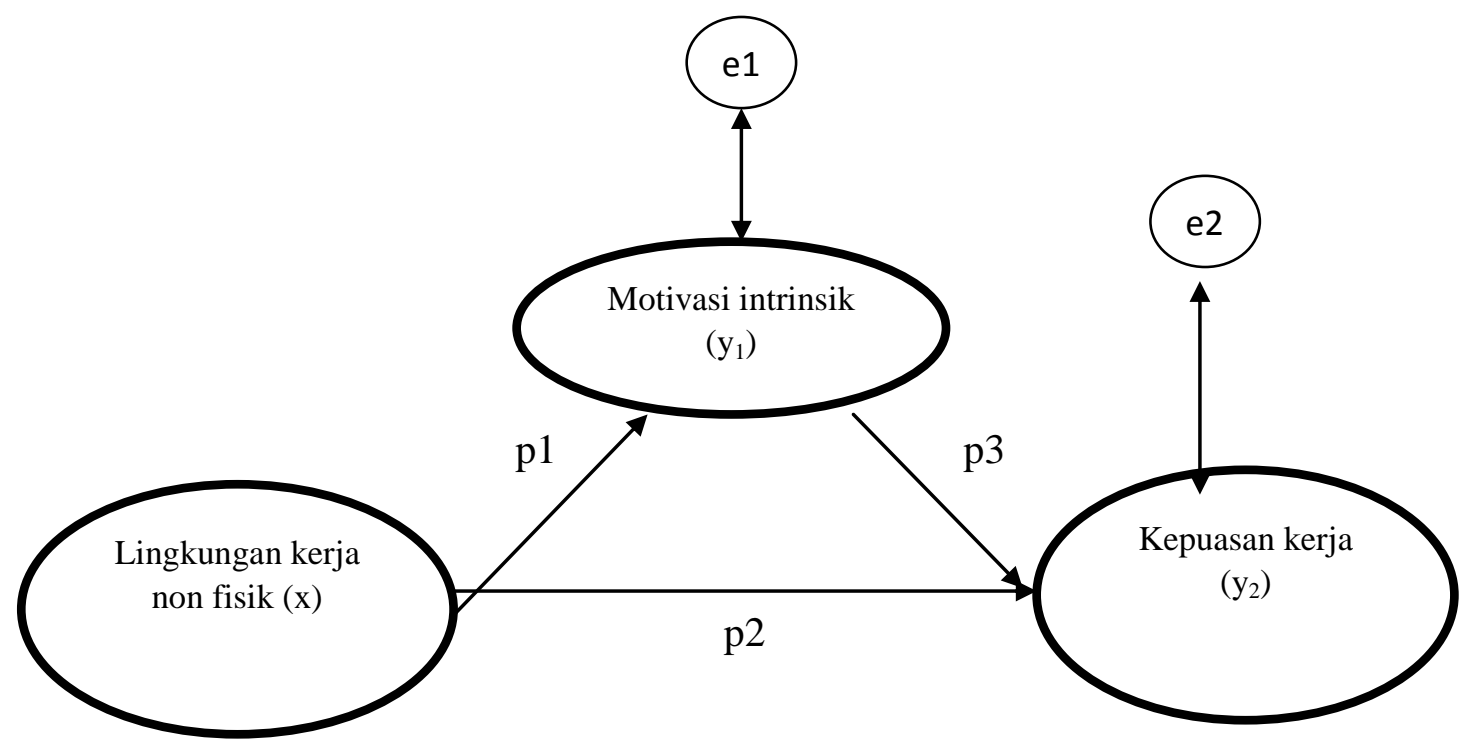

\section{Gambar 1. Model Analisis Jalur Penelitian}

Keterangan:

$\mathrm{X}=$ lingkungan kerja non fisik

$\mathrm{Y}_{1}=$ motivasi intrinsik

$\mathrm{Y}_{2}=$ kepuasan kerja karyawan

Koefisien jalur dihitung dengan dua persamaan struktural yaitu persamaan regresi yang menunjukkan hubungan yang dihipotesiskan. Dalam hal ini ada dua persamaan tersebut yaitu sebagai berikut.

Persamaan substruktur I

$\mathrm{Y}_{1}=\mathrm{p} 1 \mathrm{X}+\mathrm{e}_{1}$

Keterangan :

$\mathrm{Y}_{1}=$ Motivasi intinsik

$\alpha=$ nilai konstanta

p1= koefisien regresi variabel lingkungan kerja non fisik pada motivasi intrinsik 
$\mathrm{X}=$ lingkungan kerja non fisik

$\mathrm{e}_{1}=$ jumlah varian yang tidak diteliti dalam model penelitian

Persamaan substruktur 2

$$
\mathrm{Y}_{2}=\alpha+\mathrm{p} 2 \mathrm{X}+\mathrm{p} 3 \mathrm{Y}_{1}+\mathrm{e}_{2}
$$

Keterangan:

$\mathrm{Y}_{2}=$ Kepuasan kerja

$\alpha=$ nilai konstanta

p2 = lingkungan kerja non fisik pada kepuasan kerja

p3 = motivasi intrinsik pada kepuasan kerja

$\mathrm{X}=$ lingkungan kerja non fisik

$\mathrm{Y}_{1}=$ Motivasi intrinsik

$\mathrm{e}_{2}=$ jumlah varian yang tidak diteliti dalam model penelitian

\section{HASIL DAN PEMBAHASAN}

Uji validitas dilakukan untuk menguji seberapa baik instrumen penelitian mengukur konsep yang seharusnya diukur. Hasil penelitian yang valid yaitu bila terdapat kesamaan antara data yang terkumpul dengan data yang sesungguhnya terjadi pada objek yang diteliti.

Tabel 1 .

Hasil Uji Validitas Instrumen

\begin{tabular}{ccrrr}
\hline No & Variabel & Instrumen & Koefisien Korelasi & Keterangan \\
\hline \multirow{4}{*}{1} & $\mathrm{X}_{1}$ & 0,597 & Valid \\
& & $\mathrm{X}_{2}$ & 0,666 & Valid \\
& Lingkungan Kerja Non & $\mathrm{X}_{3}$ & 0,768 & Valid \\
& Fisik (X) & $\mathrm{X}_{4}$ & 0,489 & Valid \\
& & $\mathrm{X}_{5}$ & 0,831 & Valid \\
& & $\mathrm{X}_{6}$ & 0,847 & Valid \\
& & $\mathrm{Y}_{1.1}$ & 0,928 & Valid \\
& Motivasi Intrinsik (Y1) & $\mathrm{Y}_{1.2}$ & 0,903 & Valid \\
& & $\mathrm{Y}_{1.3}$ & 0,575 & Valid \\
& & $\mathrm{Y}_{2.1}$ & 0,921 & Valid \\
& & $\mathrm{Y}_{2.2}$ & 0,679 & Valid \\
& & $\mathrm{Y}_{2.3}$ & 0,926 & Valid \\
& & $\mathrm{Y}_{2.4}$ & 0,606 & Valid \\
& Kepuasan Kerja (Y2) & $\mathrm{Y}_{2.5}$ & 0,810 & Valid \\
\hline
\end{tabular}

Tabel 1 menunjukkan bahwa seluruh indikator pernyataan dalam variabel

lingkungan kerja non fisik, motivasi intrinsik dan kepuasan kerja memiliki 
korelasi item total (pearson correlation) lebih dari 0,30 sehingga seluruh indikator tersebut memenuhi syarat validitas data.

Uji reliabilitas digunakan untuk mengukur konsistensi dari instrumen. Instrumen yang reliable adalah instrumen yang bila digunakan beberapa kali untuk mengukur objek yang sama, akan menghasilkan data yang sama. Variabel yang dapat dinyatakan reliable apabila koefisien alpha cronbach melebihi 0,6 yang dimana tingkat reliabilitas sebesar 0,6 merupakan indikasi reliabelnya sebuah konstruk. Hasil uji reliabilitas yang disajikan dalam Tabel 2 menunjukkan bahwa ketiga instrumen penelitian yaitu lingkungan kerja non fisik, motivasi intrinsik dan kepuasan kerja memiliki koefisien Cronbach's Alpha lebih dari 0,60. Hal ini dapat dikatakan bahwa semua instrumen reliabel sehingga dapat digunakan untuk melakukan penelitian.

\section{Tabel 2}

Hasil Uji Reliabilitas Instrumen

\begin{tabular}{llrrr}
\hline No. & \multicolumn{1}{c}{ Variabel } & $\begin{array}{c}\text { Cronbach's } \\
\text { Alpha }\end{array}$ & Standar & Keterangan \\
\hline 1 & Lingkungan Kerja Non Fisik (X) & 0,774 & 0,600 & Reliabel \\
2 & Motivasi Intrinsik (Y1) & 0,833 & 0,600 & Reliabel \\
3 & Kepuasan Kerja (Y2) & 0,802 & 0,600 & Reliabel \\
\hline \multicolumn{2}{l}{ Sumber: Data diolah, 2018 }
\end{tabular}

Data karakteristik responden merupakan data responden yang dikumpulkan untuk mengetahui profil responden penelitian. Hasil penelitian yang dilakukan pada pegawai dinas pendapatan Daerah Badung Mangusada, diketahui karakteristik responden yang meliputi tiga aspek, yaitu jenis kelamin, usia, pendidikan terakhir. Berikut data karakteristik responden dengan jumlah responden sebanyak 187 orang. 
Tabel 3

Karakteristik Responden

\begin{tabular}{|c|c|c|c|}
\hline \multirow[b]{2}{*}{ No } & \multirow[b]{2}{*}{ Jenis Kelamin } & \multicolumn{2}{|c|}{ Jumlah } \\
\hline & & Orang & Persentase \% \\
\hline 1 & Laki-laki & 90 & 48,13 \\
\hline \multirow[t]{3}{*}{2} & Perempuan & 97 & 51,87 \\
\hline & Jumlah & 187 & 100 \\
\hline & & \multicolumn{2}{|c|}{ Jumlah } \\
\hline No & Usia (Tahun) & Orang & Persentase \% \\
\hline 1 & $20-30$ & 18 & 9,63 \\
\hline 2 & $31-40$ & 59 & 31,55 \\
\hline 3 & $41-50$ & 78 & 41,71 \\
\hline 4 & $51-60$ & 32 & 17,11 \\
\hline \multirow{2}{*}{\multicolumn{2}{|c|}{ Jumlah }} & 187 & 100 \\
\hline & & \multicolumn{2}{|c|}{ Jumlah } \\
\hline No & Pendidikan Terakhir & Orang & Persentase \% \\
\hline 1 & SMA & 35 & 18,72 \\
\hline 2 & D3 & 46 & 24,60 \\
\hline 3 & $\mathrm{~S} 1$ & 80 & 42,78 \\
\hline 4 & $\mathrm{~S} 2$ & 26 & 13,90 \\
\hline & Jumlah & 187 & 100 \\
\hline
\end{tabular}

Sumber: Data diolah, 2018

Tabel 3 menunjukkan tiga karakteristik dari responden yang terdiri dari jenis kelamin, usia, pendidikan terakhir. Responden pada penelitian di Dinas Pendapatan Daerah Badung, sebagian besar didominasi oleh pegawai perempuan yaitu sebanyak 97 orang dengan persentase 51,87 persen dan sisanya 90 orang pegawai berjenis kelamin laki-laki dengan persentase 48,13 persen dan kemudian untuk pengelompokan usia dominan pada usia 41-50 tahun dengan jumlah 78 orang pegawai dengan persentase 41,71 persen, usia 20-30 tahun dengan jumlah 18 orang pegawai dengan persentase 9,63 persen, usia 31-40 tahun dengan jumlah 59 orang pegawai dengan persentase 31,55 persen, dan trakhir dari usia 51-60 sebanyak 32 orang pegawai dengan persentase 17,11 persen.

Data yang diperoleh dari penyebaran kuesioner perlu dideskripsikan untuk memberikan suatu interpretasi yang jelas pada data yang diperoleh tersebut. Nilai 
rata-rata digunakan untuk mendeskripsikan hasil yang diperoleh dari instrumen penelitian. Penilaian distribusi data masing-masing variabel menggunakan rentang kriteria sebagai berikut:

(1) $1,00-1,80=$ sangat tidak baik

(2) $1,81-2,60=$ tidak baik

(3) $2,61-3,40=$ cukup baik

(4) $3,41-4,20=$ baik

(5) $4,21-5,00=$ sangat baik

Variabel kepuasan kerja diukur dengan menggunakan 5 item pernyataan yang berhubungan dengan kepuasan kerja yang dirasakan oleh pegawai Dinas Pendapatan Daerah Badung Mangusada. Berdasarkan hasil penelitian dapat diketahui jawaban responden secara rinci pada Tabel 4, sebagai berikut.

\section{Tabel 4}

\section{Deskripsi Jawaban Responden Mengenai Kepuaan Kerja}

\begin{tabular}{|c|c|c|c|c|c|c|c|c|}
\hline \multirow{2}{*}{ No } & \multirow{2}{*}{ Pernyataan } & \multicolumn{5}{|c|}{ Distribusi Jawaban } & \multirow{2}{*}{$\begin{array}{c}\text { Rata- } \\
\text { rata }\end{array}$} & \multirow[t]{2}{*}{ Ket } \\
\hline & & STS & TS & $\mathbf{N}$ & $\mathbf{S}$ & SS & & \\
\hline 1. & $\begin{array}{l}\text { Saya merasa puas dengan } \\
\text { situasi kerja }\end{array}$ & 10 & 18 & 29 & 64 & 66 & 3,84 & Baik \\
\hline 2. & $\begin{array}{l}\text { Saya merasa puas atas } \\
\text { promosi yang dilakukan oleh } \\
\text { perusahaan }\end{array}$ & 0 & 1 & 20 & 99 & 67 & 4,24 & $\begin{array}{r}\text { Sangat } \\
\text { Baik }\end{array}$ \\
\hline 3. & $\begin{array}{l}\text { Saya merasa puas dengan } \\
\text { rekan kerja yang ada di } \\
\text { perusahaan }\end{array}$ & 7 & 16 & 27 & 73 & 64 & 3,91 & Baik \\
\hline 4. & $\begin{array}{l}\text { Saya merasa puas dengan } \\
\text { atasan }\end{array}$ & 0 & 5 & 35 & 77 & 70 & 4,13 & Baik \\
\hline 5. & $\begin{array}{l}\text { Saya merasa puas dengan } \\
\text { pekerjaan yang di lakukan }\end{array}$ & 0 & 7 & 30 & 71 & 79 & 4,19 & Baik \\
\hline & $\begin{array}{ll}\text { Tota } \\
\end{array}$ & ata-rat & & & & & 4,06 & Baik \\
\hline
\end{tabular}

Sumber: Data diolah, 2018

Data pada Tabel 4 menunjukkan bahwa lima pernyataan mengenai kepuasan kerja secara keseluruhan memperoleh nilai rata-rata sebesar 4,06 dan masuk dalam kriteria baik. Nilai rata-rata tertinggi jawaban responden 
I Made Hady Sentosa, Pengaruh Lingkungan Kerja Non Fisik Terhadap...

ditunjukkan pada pernyataan "Saya merasa puas atas promosi yang dilakukan oleh perusahaan" sebesar 4,24. Selanjutnya, nilai rata-rata terendah jawaban responden ditunjukkan pada pernyataan "Saya merasa puas dengan situasi kerja", dengan nilai rata-rata sebesar 3,84. Ini berarti situasi kerja kurang memuaskan.

Variabel motivasi intrinsik diukur dengan menggunakan 3 item pernyataan yang berhubungan dengan hal-hal tentang motivasi intrinsik yang dirasakan oleh pegawai Dinas Pendapatan Daerah Badung Mangusada. Berdasarkan hasil penelitian dapat diketahui jawaban responden secara rinci pada Tabel 5 sebagai berikut.

\section{Tabel 5}

Deskripsi Jawaban Responden Mengenai Motivasi Intrinsik

\begin{tabular}{|c|c|c|c|c|c|c|c|c|}
\hline \multirow{2}{*}{ No } & \multirow{2}{*}{ Pernyataan } & \multicolumn{5}{|c|}{ Distribusi Jawaban } & \multirow{2}{*}{$\begin{array}{c}\text { Rata- } \\
\text { rata }\end{array}$} & \multirow[t]{2}{*}{ Ket } \\
\hline & & STS & TS & $\mathbf{N}$ & $\mathbf{S}$ & SS & & \\
\hline 1. & $\begin{array}{l}\text { Saya diberi kesempatan } \\
\text { berpartisifasi dalam } \\
\text { mencapai tujuan yang } \\
\text { optimal }\end{array}$ & 14 & 19 & 19 & 68 & 67 & 3,83 & Baik \\
\hline 2. & $\begin{array}{l}\text { Organisasi memberikan } \\
\text { promosi untuk kinerja } \\
\text { pegawai }\end{array}$ & 4 & 18 & 44 & 66 & 55 & 3,80 & Baik \\
\hline 3. & $\begin{array}{l}\text { Organisasi ini memotivasi } \\
\text { pegawai dengan memberikan } \\
\text { pelatihan untuk keberhasilan } \\
\text { pegawai }\end{array}$ & 0 & 5 & 14 & 105 & 63 & 4,21 & $\begin{array}{c}\text { Sangat } \\
\text { Baik }\end{array}$ \\
\hline & Tota & ata-rata & & & & & 3,95 & Baik \\
\hline
\end{tabular}

Data pada Tabel 5 menunjukkan bahwa tiga pernyataan mengenai motivasi intrinsik secara keseluruhan memperoleh nilai rata-rata sebesar 3,95 dan masuk dalam kriteria baik. Nilai rata-rata tertinggi jawaban responden ditunjukkan pada pernyataan "Organisasi ini memotivasi pegawai dengan memberikan pelatihan untuk keberhasilan pegawai" sebesar 4,21. Selanjutnya, nilai rata-rata terendah jawaban responden ditunjukkan pada pernyataan "Organisasi memberikan 
promosi untuk kinerja pegawai”, dengan nilai rata-rata sebesar 3,80. Ini berarti bahwa pegawai belum menemukan pekerjaan yang menyenangkan.

Tabel 6

Deskripsi Jawaban Responden Mengenai Lingkungan kerja Non Fisik

\begin{tabular}{|c|c|c|c|c|c|c|c|c|}
\hline \multirow{2}{*}{ No } & \multirow{2}{*}{ Pernyataan } & \multicolumn{5}{|c|}{ Distribusi Jawaban } & \multirow{2}{*}{$\begin{array}{c}\text { Rata- } \\
\text { rata }\end{array}$} & \multirow[t]{2}{*}{ Ket } \\
\hline & & STS & TS & $\mathbf{N}$ & $\mathbf{S}$ & SS & & \\
\hline 1. & $\begin{array}{l}\text { Pengawasan yang dilakukan } \\
\text { oleh perusahaan saya sudah } \\
\text { berjalan secara kondusif }\end{array}$ & 1 & 2 & 20 & 86 & 78 & 4,27 & $\begin{array}{r}\text { Sangat } \\
\text { Baik }\end{array}$ \\
\hline 2. & $\begin{array}{l}\text { Suasana kerja dalam } \\
\text { perusahaan saya } \\
\text { menyenangkan. }\end{array}$ & 0 & 1 & 19 & 98 & 69 & 4,26 & $\begin{array}{r}\text { Sangat } \\
\text { Baik }\end{array}$ \\
\hline 3. & $\begin{array}{l}\text { Imbalan yang di berikan } \\
\text { perusahaan sudah sesuai. }\end{array}$ & 7 & 17 & 36 & 74 & 53 & 3,80 & Baik \\
\hline 4 & $\begin{array}{l}\text { Pimpinan memberikan } \\
\text { perlakuan yang baik terhadap } \\
\text { saya tidak disamakan seperti } \\
\text { robot }\end{array}$ & 0 & 12 & 36 & 78 & 61 & 4,00 & $\begin{array}{r}\text { Sangat } \\
\text { Baik }\end{array}$ \\
\hline 5 & $\begin{array}{l}\text { Saya merasa aman dalam } \\
\text { lingkungan kerja }\end{array}$ & 9 & 19 & 29 & 73 & 57 & 3,80 & Baik \\
\hline 6 & $\begin{array}{l}\text { Saya menjalin hubungan } \\
\text { yang humoris dengan } \\
\text { sesama karyawan dalam } \\
\text { perusahaan }\end{array}$ & 13 & 18 & 22 & 71 & 63 & 3,81 & Baik \\
\hline & Total & ata-rata & & & & & 3,99 & Baik \\
\hline
\end{tabular}

Sumber: Data diolah, 2018

Data pada Tabel 6 menunjukkan bahwa enam pernyataan mengenai lingkungan kerja non fisik secara keseluruhan memperoleh nilai rata-rata sebesar 3,99 dan masuk dalam kriteria baik. Nilai rata-rata tertinggi jawaban responden ditunjukkan pada pernyataan "Pengawasan yang dilakukan oleh perusahaan saya sudah berjalan secara kondusif" sebesar 4,27. Selanjutnya, nilai rata-rata terendah jawaban responden ditunjukkan pada pernyataan "Saya merasa aman dalam lingkungan kerja", dengan nilai rata-rata sebesar 3,80. Ini berarti belum adanya keamanan dalam perusahaan. 
I Made Hady Sentosa, Pengaruh Lingkungan Kerja Non Fisik Terhadap...

Perhitungan koefisien path dilakukan dengan analisis regresi melalui software SPSS 18.0 for Windows, diperoleh hasil yang ditunjukan pada Tabel 7 berikut.

Tabel 7

Hasil Analisis Jalur Struktur 1

\begin{tabular}{|c|c|c|c|c|c|c|}
\hline & \multirow[t]{2}{*}{ Model } & \multicolumn{2}{|c|}{$\begin{array}{l}\text { Unstandardized } \\
\text { Coefficients }\end{array}$} & \multirow{2}{*}{$\begin{array}{c}\text { Standardized } \\
\text { Coefficients } \\
\text { Beta }\end{array}$} & \multirow[t]{2}{*}{$\mathbf{t}$} & \multirow[t]{2}{*}{ Sig. } \\
\hline & & B & Std. Error & & & \\
\hline \multirow[t]{6}{*}{1} & (Constant) & $-2.970 \mathrm{E}-16$ & .047 & & .000 & 1.000 \\
\hline & $\begin{array}{l}\text { Lingkungan Kerja Non } \\
\text { Fisik }\end{array}$ & .772 & .047 & .772 & 16.529 & .000 \\
\hline & F Hitung & & & & & 3,222 \\
\hline & Signifikansi & & & & & $\mathbf{0 , 0 0 0}$ \\
\hline & $\mathbf{R}_{1}$ Square & & & & & 0,596 \\
\hline & Adjusted $R_{1}$ Square & & & & & 0,594 \\
\hline
\end{tabular}

Sumber: Data diolah, 2018

Berdasarkan hasil analisis jalur substruktur 1 seperti yang disajikan pada

Tabel, maka persamaan strukturalnya adalah sebagai berikut.

$$
\mathrm{Y} 1=0,772 \mathrm{X} 1+\mathrm{e}_{1}
$$

\section{Tabel 8}

Hasil Analisis Jalur Struktur 2

\begin{tabular}{|c|c|c|c|c|c|c|}
\hline & \multirow{2}{*}{ Model } & \multicolumn{2}{|c|}{$\begin{array}{c}\text { Unstandardized } \\
\text { Coefficients }\end{array}$} & \multirow{2}{*}{$\begin{array}{c}\text { Standardized } \\
\text { Coefficients } \\
\text { Beta }\end{array}$} & \multirow{2}{*}{$\mathbf{t}$} & \multirow{2}{*}{ Sig. } \\
\hline & & B & $\begin{array}{l}\text { Std. } \\
\text { Error }\end{array}$ & & & \\
\hline \multirow[t]{7}{*}{1} & (Constant) & $\begin{array}{r}-4.015 \mathrm{E}- \\
15\end{array}$ & .040 & & .000 & 1.000 \\
\hline & $\begin{array}{l}\text { Lingkungan Kerja Non } \\
\text { Fisik }\end{array}$ & .450 & .063 & .450 & 7.150 & .000 \\
\hline & Motivasi Intrinsik & .443 & .063 & .443 & 7.053 & .000 \\
\hline & F Hitung & & & & & 221,366 \\
\hline & Signifikansi & & & & & $\mathbf{0 , 0 0 0}$ \\
\hline & $\mathbf{R}_{2}$ Square & & & & & 0,706 \\
\hline & Adjusted $R_{2}$ Square & & & & & $\mathbf{0 , 7 0 3}$ \\
\hline
\end{tabular}

Berdasarkan hasil analisis jalur substruktur 2 seperti yang disajikan pada Tabel, maka persamaan strukturalnya adalah sebagai berikut :

$$
\mathrm{Y} 2=0,450 \mathrm{X} 1+0,443 \mathrm{Y} 1+\mathrm{e}_{2}
$$


Berdasarkan model substruktur 1 dan substruktur 2, maka dapat disusun model diagram jalur akhir. Sebelum menyusun model diagram jalur akhir, terlebih dahulu dihitung nilai standar eror sebagai berikut :

$\mathrm{Pe}_{\mathrm{i}}=\sqrt{1-\mathrm{R}_{\mathrm{i}}^{2}}$

Substruktur 1:

$\mathrm{Pe}_{1}=\sqrt{1-0,596}=\sqrt{0,404}=0,636$

Substruktur 2:

$\mathrm{Pe}_{2}=\sqrt{1-0,706}=\sqrt{0,294}=0,542$

Berdasarkan perhitungan pengaruh error (Pei), didapatkan hasil pengaruh error $\left(\mathrm{Pe}_{1}\right)$ sebesar 0,636 dan pengaruh error $\left(\mathrm{Pe}_{2}\right)$ sebesar 0,542. Hasil koefisien determinasi total adalah sebagai berikut :

$$
\begin{aligned}
\mathrm{R}_{\mathrm{m}} & =1-\left(\mathrm{Pe}_{1}\right)^{2}\left(\mathrm{Pe}_{2}\right)^{2} \\
& =1-(0,636)^{2}(0,542)^{2} \\
& =1-(0,404)(0,294) \\
& =1-0,118=0,882
\end{aligned}
$$

Nilai determinasi total sebesar 0,882 mempunyai arti bahwa sebesar 88,2 persen variasi kepuasan kerja dipengaruhi oleh variasi lingkungan kerja non fisik, dan motivasi intrinsik, sedangkan sisanya sebesar 11,8 persen djelaskan oleh faktor lain yang tidak dimasukkan ke dalam model.

Berdasarkan hasil analisis pengaruh lingkungan kerja non fisik terhadap motivasi intrinsik diperoleh nilai signifikansi sebesar 0,000 dengan nilai koefisien beta 0,772 . Nilai signifikansi $0,000<0,05$ mengindikasikan bahwa $\mathrm{H}_{0}$ ditolak dan 
I Made Hady Sentosa, Pengaruh Lingkungan Kerja Non Fisik Terhadap...

$\mathrm{H}_{1}$ diterima. Hasil ini mempunyai arti bahwa lingkungan kerja non fisik berpengaruh positif dan signifikan terhadap motivasi intrinsik karyawan di Dinas Pendapatan Daerah Badung.

Berdasarkan hasil analisis pengaruh lingkungan kerja non fisik terhadap kepuasan kerja diperoleh nilai signifikansi sebesar 0,000 dengan nilai koefisien beta 0,450 Nilai signifikansi $0,000<0,05$ mengindikasikan bahwa $\mathrm{H}_{0}$ ditolak dan $\mathrm{H}_{1}$ diterima. Hasil ini mempunyai arti bahwa lingkungan kerja non fisik berpengaruh positif dan signifikan terhadap kepuasan kerja karyawan di Dinas Pendapatan Daerah Badung.

Berdasarkan hasil analisis pengaruh motivasi intrinsik terhadap kepuasan kerja diperoleh nilai signifikansi sebesar 0,000 dengan nilai koefisien beta 0,443. Nilai Sig. t 0,000 $<0,05$ mengindikasikan bahwa $\mathrm{H}_{0}$ ditolak dan $\mathrm{H}_{1}$ diterima. Hasil ini mempunyai arti bahwa motivasi intrinsik berpengaruh positif dan signifikan terhadap kepuasan kerja karyawan di Dinas Pendapatan Daerah Badung.

Hasil koefisien jalur pada hipotesis penelitian dapat digambarkan pada Gambar 2. 


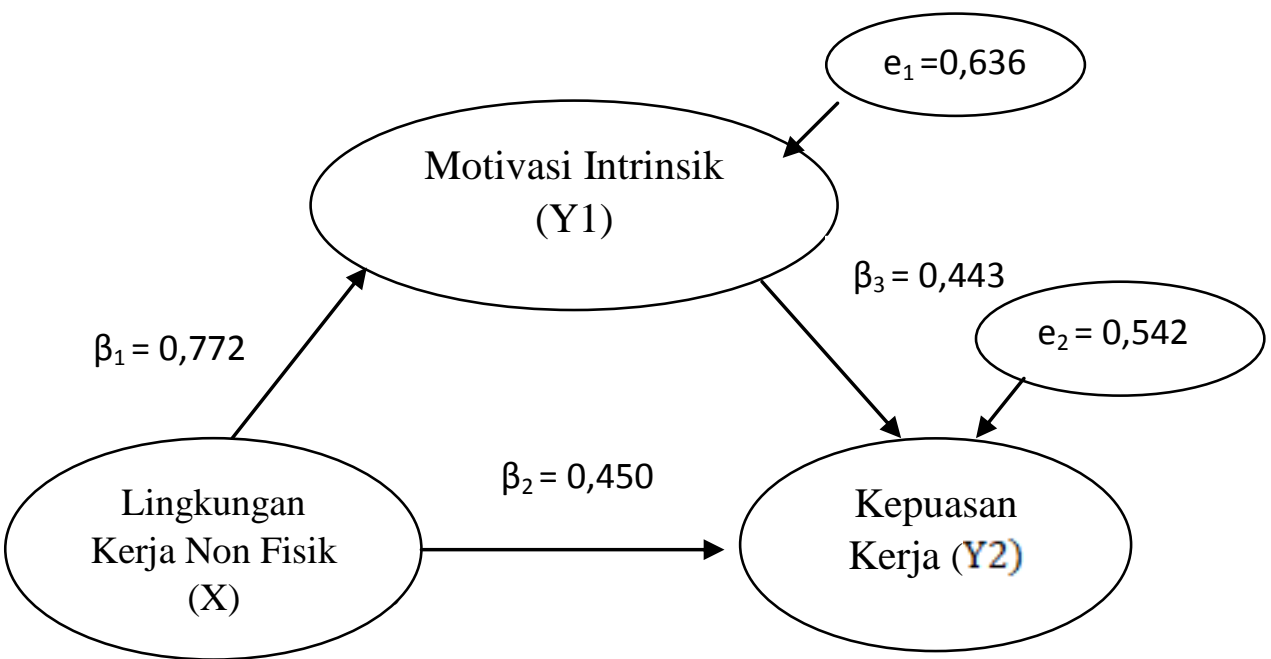

Gambar 2. Validasi Model Diagram Jalur Akhir

Sumber: Data diolah, 2018

Berdasarkan diagram jalur pada Gambar 1, maka dapat dihitung besarnya pengaruh langsung dan pengaruh tidak langsung serta pengaruh total antar variabel. Perhitungan pengaruh antar variabel dirangkum dalam Tabel berikut.

Tabel 9

Pengaruh Langsung dan Pengaruh Tidak Langsung serta Pengaruh Total Lingkungan Kerja Non Fisik (X), Motivasi Intrinsik (Y1), dan Kepuasan Kerja (Y2)

\begin{tabular}{ccccc}
\hline & $\begin{array}{c}\text { Pengaruh } \\
\text { Variabel }\end{array}$ & $\begin{array}{c}\text { Pengaruh } \\
\text { Langsung }\end{array}$ & $\begin{array}{c}\text { Pengaruh Tidak Langsung } \\
\text { Melalui Motivasi Intrinsik } \\
(\text { Y1 })(\boldsymbol{\beta} \text { 1 x } \boldsymbol{\beta 3})\end{array}$ & $\begin{array}{c}\text { Pengaruh } \\
\text { Total }\end{array}$ \\
\hline $\boldsymbol{\beta} 1$ & $\mathrm{X} \rightarrow \mathrm{Y} 1$ & 0,772 & - & 0,772 \\
$\boldsymbol{\beta 2}$ & $\mathrm{X} \rightarrow \mathrm{Y} 2$ & 0,450 & 0,342 & 0,792 \\
$\boldsymbol{\beta 3}$ & $\mathrm{Y} 1 \rightarrow \mathrm{Y} 2$ & 0,443 & - & 0,443 \\
\hline Sumber:
\end{tabular}

Pengujian berikutnya adalah uji kelayakan model atau yang lebih populer disebut sebagai uji F (ada juga yang menyebutnya sebagai uji simultan model) merupakan tahapan awal mengidentifikasi model regresi yang diestimasi layak atau tidak. Layak (andal) disini maksudnya adalah model yang diestimasi layak digunakan untuk menjelaskan pengaruh variabel-variabel bebas terhadap variabel 
I Made Hady Sentosa, Pengaruh Lingkungan Kerja Non Fisik Terhadap...

terikat. Nama uji ini disebut sebagai uji F, karena mengikuti mengikuti distribusi F yang kriteria pengujiannya seperti One Way Anova. Hasil uji kelayakan model pada penelitian ini ditujukkan oleh Tabel 10 dan 11.

Tabel 10.

Uji Anova Struktur 1

\begin{tabular}{llrrrrr}
\hline Model & & Sum of Squares & df & Mean Square & \multicolumn{1}{c}{ F } & Sig. \\
\hline 1 & Regression & 110.905 & 1 & 110.905 & 273.222 & $.000^{\mathrm{a}}$ \\
& Residual & 75.095 & 185 & .406 & & \\
& Total & 186.000 & 186 & & & \\
\hline Sumber: & Data diolah 2018 & & & & &
\end{tabular}

Tabel hasil uji anova struktur 1 (UJI F) di atas, diperoleh nilai kelompok pembanding $=1$, nilai dalam kelompok penyebut $=185$, pada alfa $=0.05$ maka nilai $\mathrm{F}$ tabelnya adalah $\mathrm{F} 0,05(1,185)=3,89$. Sedang $\mathrm{F}$ hitung $=273,222$. Nilai Fhitung > Ftabel, 273,222 > 3,89, dengan nilai sig. 0,000 < 0,05. Maka H0 ditolak pada taraf nyata 0,05 (H1 diterima). Kesimpulannya, pada kelompok yang diuji memiliki perbedaan yang nyata (signifikan), sehingga dapat dikatakan bahwa lingkungan kerja non fisik berpengaruh secara simultan terhadap motivasi intrinsik.

Tabel 11.

Uji Anova Struktur 2

\begin{tabular}{llrrrrr}
\hline Model & & Sum of Squares & df & Mean Square & F & Sig. \\
\hline 1 & Regression & 131.393 & 2 & 65.696 & 221.366 & $.000^{\mathrm{a}}$ \\
& Residual & 54.607 & 184 & .297 & & \\
& Total & 186.000 & 186 & & & \\
\hline
\end{tabular}

Sumber: Data diolah, 2018

Tabel hasil uji anova struktur 2 (UJI F) di atas, diperoleh nilai kelompok pembanding $=2$, nilai dalam kelompok penyebut $=186$, pada alfa $=0.05$ maka nilai $F$ tabelnya adalah $F 0,05(2,186)=3,04$. Sedang F hitung $=221,366$. Nilai Fhitung $>$ Ftabel, 221,366 > 3,04, dengan nilai sig. 0,000 < 0,05. Maka H0 ditolak pada taraf nyata 0,05 (H1 diterima). Kesimpulannya, pada kelompok yang 
diuji memiliki perbedaan yang nyata (signifikan), sehingga dapat dikatakan bahwa lingkungan kerja non fisik, dan motivasi intrinsik berpengaruh secara simultan terhadap kepuasan kerja.

Hasil pengujian hipotesis variabel lingkungan kerja non fisik terhadap motivasi intrinsic karyawan, menunjukkan pengaruh positif dan signifikan dari variabel lingkungan kerja non fisik terhadap motivasi intrinsic. hasil penelitian yang dilakukan Wicaksono (2013), Mujib (2013), Rochani C.A (2008), Sari (2012) dan Anwar (2013) yang menyatakan bahwa lingkungan kerja non fisik berpengaruh positif terhadap motivasi intrinsic karyawan. Lingkungan kerja merupakan keseluruhan sarana dan prasarana kerja yang ada disekitar pegawai yang dapat mempengaruhi pelaksanaan pekerjaan meliputi lingkungan kerja fisik maupun lingkungan non fisik, dimana lingkungan kerja non fisik seperti adanya hubungan kerja yang baik antar pegawai dan atasan akan membuat pegawai merasa nyaman dalam bekerja sehingga dapat memotivasi diri pegawai secara intrinsik untuk menyelesaikan pekerjaan

Hasil pengujian hipotesis variabel lingkungan kerja non fisik terhadap kepuasan kerja karyawan, menunjukkan pengaruh positif dan signifikan dari variabel lingkungan kerja non fisik terhadap kepuasan kerja karyawan. hasil penelitian yang dilakukan Jain et al. (2014), Osibanjo et al. (2014), Indrawati (2012), Rumada dan Utama (2013) dan Handaru (2013) menyatakan bahwa lingkungan kerja non fisik berpengaruh positif terhadap kepuasan kerja karyawan. hasil penelitian ini menunjukkan Pada fasilitas kondisi kerja yang baik sisi lain, 
I Made Hady Sentosa, Pengaruh Lingkungan Kerja Non Fisik Terhadap...

penyegaran dan fasilitas rekreasi, kesehatan dan keselamatan, menyenangkan di tempat kerja meningkatkan tingkat kepuasan kerja.

Hasil pengujian hipotesis variabel motivasi intrinsic terhadap kepuasan kerja menunjukkan pengaruh positif dan signifikan dari variabel motivasi intrinsic terhadap kepuasan kerja karyawan. hasil penelitian yang dilakukan Guritno dan Heru (2016), Siagian (2004), Indrawati (2012), Handoko (2012), dan Nalendra (2008) menyatakan bahwa motivasi intrinsic berpengaruh positif terhadap terhadap kepuasan kerja karyawan. hasil penelitian ini menunjukkan Motivasi kerja merupakan suatu semangat yang tercermin dalam kedisiplinan kerja, sehingga akan mampu menciptakan kepuasan kerja bagi setiap pegawai/karyawan.

\section{SIMPULAN DAN SARAN}

Hasil penelitian menujukkan bahwa lingkungan kerja non fisik memiliki pengaruh positif dan signifikan terhadap kepuasan kerja pada pegawai di dinas pendapatan Daerah Badung Mangusada. Lingkungan kerja non fisik memiliki pengaruh positif dan signifikan terhadap motivasi intrinsik pada pegawai di dinas pendapatan Daerah Badung Mangusada. Motivasi intrinsik memiliki pengaruh positif dan signifikan terhadap kepuasan kerja pada pegawai di dinas pendapatan Daerah Badung Mangusada.

Saran yang dapat diberikan dari hasil penelitian adalah 1) organisasi agar dapat lebih memperhatikan pimpinan organisasi dalam mengidentifikasi peluang atau visi yang baru dalam mencapai tujuan pelayanan di dinas pendapatan yang lebih unggul, dimana harapan peluang baru ini nantinya dapat dikembangkan 
dengan baik, 2) pimpinan organisasi agar lebih menunjukan perhatian langsung kepada pegawai dengan memperhatikan kenyamanan pegawai ketika melaksanakan tugas dan juga memperhatikan beban kerja pegawai di setiap ruangan yang nantinya dapat lebih menumbuhkan rasa puas dalam bekerja, 3) organisasi senantiasa menjaga komunikasi yang sehat dengan seluruh pegawai, sehingga pegawai akan dapat memahami suatu pekerjaan, tugas dan tanggungjawab bila pegawai tersebut memperoleh penjelasan, petunjuk, instruksi yang jelas dari atasan, disamping itu pegawai memperoleh kesempatan bertanya, memberi saran atau usul, menyampaikan keluhan dan memberi laporan kepada atasan.

\section{REFERENSI}

Ahmad, H., Khursheed Ahmad, and Idrees Ali Shah. 2010. Relationship between job satisfaction, job performance attitude towards work and organizational commitment. European Journal of Social Sciences, 18(2), pp: 257-267.

Anwar, Hairil. 2013. Pengaruh Lingkungan Kerja Pegawai terhadap Semangat Kerja Pegawai Kantor Imigrasi Kota Samarinda. eJournal Ilmu Pemerintahan, 1 (1), h: 348-358.

Baard, Paul P., Edward L. Deci and Richard M. Ryan. 2004. Intrinsic Need Satisfaction: A Motivational Basis of Performance and Well-Being in Two Work Settings. Journal of Applied Social Psychology, 34(10), pp: 2045-2068.

Brown, S. and Tobias Huning, 2010. Intrinsic motivation and job satisfaction: The intervening role of goal orientation. International Journal Proceedings of the Academy of Organizational Culture, Communications and Conflict, 15(1), pp: 1-13.

Choong, Yuen-Onn, Kee-Luen Wong and Teck-Chai Lau. 2011. Intrinsic Motivation And Organizational Commitment In The Malaysian 
I Made Hady Sentosa, Pengaruh Lingkungan Kerja Non Fisik Terhadap...

Private Higher Education Institutions: An Empirical Study. Journal of Arts, Science and Commerce, 2(4), pp: 91-100.

Dhermawan, A.A.Ngurah Bagus, Sudibya Adnyana I Gde dan Utama Mudiarta I Wayan. 2012. Pengaruh Motivasi, Lingkungan Kerja, Kompetensi, dan Kompetensi Terhadap Kepuasan Kerja dan Kinerja Pegawai. Jurnal Manajemen, Strategi Bisnis dan Kewirausahaan (Matrik). 6(2), pp: 72-80.

Dewi, Matalia Wirmaya Putu. 2012. Pengaruh Kepemimpinan dan Hubungan Kerja Terhadap Pengembangan Karir dan Kepuasan Kerja Pegawai, Jurnal Manajemen, Strategi Bisnis dan Kewirausahaan (Matrik). 6(1), h: 16-25.

Guritno, B. dan Heri Prabowo. 2016. Analisis pengaruh motivasi intrinsik terhadap kepuasan kerja yang berdampak pada kinerja karyawan di PT. Jhons GF Semarang. Bulletin bisnis dan manajemen, 2(2), pp: 4658.

Handaru Agung Wahyu, Utomo Try Dan Sudiarditha I Ketut R. 2013. Pengaruh Lingkungan Kerja, Kompensasi Dan Komitmen Organisasi Terhadap Kepuasan Kerja Karyawan Di Rs "X”. Jurnal Riset Manajemen Sains Indonesia (JRMSI). 4(1), pp: 11-22.

Hasibuan, Melayu. 2009. Manajemen Sumber Daya Manusia. Edisi Revisi: Bumi Aksara Jakarta.

Hasibuan SP. Malayu. 2007. Manajemen Sumber Daya Manusia. Edisi Revisi: Bumi Aksara Jakarta.

Herzberg, Fredrick. 2008. One More Time: How do You Motivate Employees? Boston : Harvard Bussiness Press.

Ibrahim, M. and Veronica Adu Brobbey. 2015. Impact Of Motivation On Employee Performance: The Case Of Some Selected Micro Finance Companies In Ghana. International Journal of Economics, Commerce and Management, 3(11), pp: 1218-1236.

Indrawati Ayu Desi. 2012. Faktor Penentu Kepuasan Kerja Pegawai Badan Perencanaan Dan Pembangunan Daerah (BAPPEDA) Kabupaten Tabanan. Jurnal Manajemen, Strategi Bisnis dan Kewirausahaan. 6(1), pp: 21-34.

Jain, ruchi dan surinder kaur. 2014.impact of word envirotment on job satisfaction. Internasional jurnal of scientificand research publications, 4(1), pp:1-8. 
Kabungaidze, $\mathrm{T}$ and Nomakholwa Mahlatshana. 2013. The Impact of Job Satisfaction and Some Demographic Variables on Employee Turnover Intentions. International Journal of Business Administration, 4(1), pp: 53-65.

Manullang, 2008, Dasar-Dasar Manajemen, Yogyakarta: Ghalia Indonesia (GI)

Martoyo Susilo. 2000. Manajemen Sumber Daya Manusia. Yogyakarta: BPFE.

Murti, H. dan Veronika Agustini Srimulyani. 2013. Pengaruh Motivasi Terhadap Kinerja Pegawai Dengan Variabel Pemediasi Kepuasaan Kerja Pada PDAM Kota Madiun. Jurnal Riset Manajemen dan Akuntansi, 1(1), pp: 10-17.

Musriha Dr. 2011. Influences Of Work Behavior, Work Environment And Motivation In Clove Cigarette Factories In Kudus, Indonesia. Academic Research International Journal. 1(3), pp: 64-70.

Mathis Robert L. Dan jackson John H. 2002. Human Resoursce management, ahli bahasa. Selemba empat. Jakarta.

Nalendra, Evan. 2008. Pengaruh kompensasi dan motivasi kerja terhadap kepuasan kerja karyawan pada PT. Karya Sejati Vidyatama. Tesis Program Studi Manajemen Unika Soegijapranata, Semarang.

Nawawi, Hadari. 2001. Manajemen Sumber Daya Manusia Untuk Bisnis Yang Kompetitif. Cetakan Keempat. Yogyakarta: Gajah Mqada Univesity Press.

Nitisemito, Alexs. 2000. Manajemen Suatu Dasar dan Pengantar. Jakarta: Ghalia Indonesia.

Osibanjo A.O, Abiodun A, and Adeniji A.A.2014. impact ofjob envirotment on job satisfaction and commitment among nigeria nurses. Jurnal of south african business and research, 1(1), pp: 1-11.

Purwaningrum, H., Ari Pradanawati dan Reni Shinta Dewi. 2012. Pengaruh Komunikasi Internal, Kompensasi, Lingkungan Kerja Terhadap Kinerja Karyawan Melalui Motivasi Pada Cv. Medinda Semarang. Jurnal Ilmu Administrasi Bisnis, 1(2), h: 261-272.

Pushpakumari, M. D. 2008. The impact of job satisfaction on job performance: An empirical analysis. In City Forum, 9(1), pp: 89-105. 
I Made Hady Sentosa, Pengaruh Lingkungan Kerja Non Fisik Terhadap...

Rainey, Hal G. and Steinbauer, P. 1999. Galloping Elephants: Developing Elements of a Theory of Effective Government Organizations. Journal of Public Administration Research and Theory, 9(1), pp: 132.

Retnaningsih Sudarwanti. 2007 Analisis Pengaruh Keadilan Kompensasi, Peran Kepemimpinan, Dan Kepuasan Kerja Terhadap Komitmen Organisasi Dalam Meningkatkan Kinerja Karyawan (Studi Kasus: Pada Sentral Pengolahan Pos Semarang). Tesis Program Studi Magister Manajemen Program Pasca Sarjana Universitas Diponegoro. Semarang.

Rezita, revi. 2014. Pengaruh lingkungan kerja terhadap motivasi kerja karyawan di bank jatim cabang utama surabaya. Jurnal universitas negeri surabaya, 1(1), 1-15.

Rivai, V., 2004. Manajemen Sumber Daya Manusia untuk Perusahaan. Jakarta: PT. Raja Grafindo Persada.

Robbins, Stephen P. 2010. Manajemen. Edisi Kesepuluh. Jakarta: Erlangga.

Rochani C.A. 2008. Analisis Pengaruh Lingkungan Kerja, Komunikasi Dan Pengawasan Terhadap Motivasi Karyawan Perusahaan Album Sankyo. Skripsi Jurusan Manajemen Fakultas Ekonomi Universitas Katolik Soegijapranata. Semarang.

Rumada Gede Dan Utama I Wayan Mudiartha. 2013. Pengaruh Kompensasi, Kepemimpinan, Dan Lingkungan Kerja Fisik Terhadap Kepuasan Kerja Karyawan Hotel Taman Harum Ubud Gianyar. E-Jurnal Manajemen Universitas Udayana. 2(1), pp: 42-50.

Sari Oktariansyah. 2012. Pengaruh Kepemimpinan Dan Lingkungan Kerja Fisik Terhadap Motivasi Kerja Karyawan CV. Sedulur Palembang. Jurnal Media Wahana Ekonomika. 9(2), pp: 52-63.

Sedarmayanti. 2001. Sumber daya manusia dan produktivitas kerja. Jakarta: mandar maju.

Sedarmayanti.2009. Sumber Daya Manusia dan Produktivitas Kerja. Bandung: CV Mandar Maju.

Shalley, C. E. Gilson, L., \& Blum, T. C. 2000. Matching creativity requirements and the work environment: Effects on satisfaction and intentions to leave. Academy of Management Journal, 43, 215-223. 
Siagian, Sondang P. 2004. Manajemen sumber daya manusia. Jakarta: Bumi Aksara.

Sidanti, heny. 2015. Pengaruh Lingkungan Kerja, Disiplin Kerja Dan Motivasi Kerja Terhadap Kinerja Pegawai Negeri Sipil Di Sekretariat Dprd Kabupaten Madiun. Jurnal JIBEKA, 9(1), h: 44-53.

Sintha Dewi Kadek. 2013. Pengaruh Gaya Kepemimpinan Transformasional Terhadap Kepuasan Kerja Karyawan Dan Komitment Organisasi Pada PT. KPM. Jurnal Manajemen, Strategi Bisnis Dan Kewirausahaan. 7 (2), pp: 21-32.

Sugiono. 2012. Metode Penelitian Bisnis (Pendekatan Kuantitatif, Kualitatif dan $R \& D)$. Bandung: ALFABETA.

Suwardi dan Joko Utomo. 2011. Pengaruh Motivasi Kerja, Kepuasan Kerja, Dan Komitmen Organisasional terhadap Kinerja Pegawai (Studi Pada Pegawai Setda Kabupaten Pati). Analisis Manajemen. 5(1), pp: 75 86.

Tohardi Ahmad. 2002. Pemahaman Praktis Manajemen Sumber Daya Manusia. Bandung: Mandar Maju.

Westerman James W. 2007. The Effects of Work Environment on the PersonalityPerformance Relationship: An Exploratory Study. Internasional Journal of Managerial Issues, 19(2), pp: 288-305.

Wicaksono Welly Anggun. 2013. Pengaruh Lingkungan Kerja Terhadap Motivasi Kerja Pada Perusahaan Daerah Air Minum Tirta Khatulistiwa Kota Pontianak. Jurnal Manajemen Update. 2(2), pp: 80-92.

Yudistira, Cokorda Gede Putra \& Siwantara I Wayan. 2012. Pengaruh Gaya Kepemimpinan Transformasional Ketua Koperasi Dan Kompetensi Kecerdasan Emosional Manajer Koperasi Terhadap Kepuasan Kerja dan Kinerja Manajer Koperasi di Kabupaten Buleleng, Jurnal Manajemen, Strategi Bisnis dan Kewirausahaan (Matrik). 6(1), pp: 43-55.

Zeinabadi, Hassanreza. 2010. Job satisfaction and organizational commitment as antecedents of organizational citizenship behavior (OCB) of teachers. Procedia-Social and Behavioral Sciences, 5(1), pp: 998-1003.

Zhang, Xiaomeng and Kathryn M. Bartol. 2010. Linking Empowering Leadership And Employee Creativity: The Influence Of Psychological Empowerment, Intrinsic Motivation, And Creative Process Engagement. Academy of Management Journal, 53(1), pp: 107-128. 
I Made Hady Sentosa, Pengaruh Lingkungan Kerja Non Fisik Terhadap... 